\title{
Tumor therapy with Amanita phalloides (Death Cap): stabilization of mammary duct cancer
}

Isolde Riede*

Im Amann 7, Ueberlingen D-88662, Germany

\begin{abstract}
Molecular events that cause tumor formation enhance a number of HOX genes, called switch genes, coding for RNApolymeraseII transcription factors. Thus, in tumor cells, RNApolymeraseII is more active than in other somatic cells. Amanita phalloides contains amanitin which inhibits RNApolymeraseII. Partial inhibition with amanitin influences tumor cell - but not normal cell - activity. To widen the treatment spectrum, dilutions of Amanita phalloides, containing amanitin, are applied to a patient with mammary duct cancer. For monitoring tumormarkers, different doses of amanitin are applied. The former duplication time of tumor growth represented three months; however within a period of 18 months the patient can be stabilized without further growth of the tumor. There are also no severe symptoms, no liver damage and no continuous erythrocyte deprivation. This new principle of tumor therapy shows high potential to provide a medical treatment.
\end{abstract}

Keywords Amanita therapy, tumor therapy, breast cancer, mammary ducts cancer, hox genes, switch genes

\section{INTRODUCTION}

Successful tumor therapy is based upon the reduction of tumor cells without affecting somatic cells - especially immune cells. Amanita therapy has been developed to meet this goal, and preliminary pilot cases, for example with B-Cell Chronic Lymphatic Leukemia (Riede, 2010) showed the potential of stabilizing the disease without severe side effects.

Early physicians and cell biologists defined the evolving stages in tumor formation: the initiation, promotion and progression of a tumor. Genetics and molecular biology have been able to refine the initial picture at the molecular level. Tumor initiation, the arising of a tumor cell, can be caused by a mutation of a proliferative gene, breaking the cell cycle and allowing replication (Riede, 1997). Alone this mutation might not always initiate the more undifferentiated and aggressive growth of the cells resulting in a cancer disease. Oncogene and tumor suppressor mutations can be added to reduce the differentiation levels of the cell and thereby lead to limited tumor development or growth (Bishop, 1985, Barrett et al., 1986). However, one single mutation can be sufficient to produce a progressive leukemic cell population ( $\mathrm{Gu}$ et al., 1993).

Homeobox (HOX) genes play key roles in embryogenesis and tissue differentiation, as well as define the number of cell cycles during embryogenesis - dictating the size of organ structures. Their role in tumor formation is not yet fully understood; however, a number of altered HOX gene expressions in breast cancer have been reported that might affect tumor cell growth (Yang et al., 2010; Svingen and Tonissen, 2003). Reducing HOX gene Six1 expression by

"Correspondence: Isolde Riede

E-mail: riede@ tumor-therapie.info

Received May 30, 2011; Accepted November 22, 2011; Published November 30, 2011

doi: http://dx.doi.org/10.5677/tang.2011.0006

(02011 by Association of Humanitas Medicine
microRNA-185 suppresses tumor growth in human cancers (Imam et al., 2010).

Molecular events that cause tumor formation enhance a number of HOX genes, called switch genes (Rozovskaia et al., 2001, Svingen and Tonissen, 2003), coding for RNApolymeraseII (RNAP) transcription factors. Thus, in tumor cells RNAP is more active than in somatic cells. The down-regulation of homeobox genes in MLL-rearranged acute leukemia reduces proliferation (Orlovsky et al., 2011). Thus, at this central switch point in tumor formation, molecular intervention assures therapeutic success (Riede, 2004).

In the classical sense, Amanita (A.) phalloides has been used as a remedy against the fear of death for hundreds of years In the molecular sense, this remedy was newly discovered as a growth inhibitor specifically for tumor cells. The drug in the extract of A. phalloides, amanitin, blocks RNAP in all cells. In most cells of adults, RNAP is used to a small extent. Partial inhibition of this molecule has no effect on normal body cells but inhibits the activity of tumor cell growth. The immune system recognizes and lyses tumor cells, and the lysis of cells is monitored by lactatedehydrogenase (LDH) levels in serum. Lysing tumor cells might release intracellular proteins like cytokeratins, thus serum levels of these tumormarkers can increase during digestion of the cells.

For tumor treatment, dilutions of D2, D3 and D4 are useful The drug accumulates and is slowly metabolized by the body, so treatment begins at a low level, gradually increasing to the effective dosage by regularly monitoring tumor markers. The general rule is the more tumor mass found in the body and the more aggressive the tumor, the quicker a basic level should be built up - and vice-versa.

For prophylaxis, following an operation with small residual tumor masses, 5 drops of D4 per day are usually sufficient to prevent growth of residual tumor cells and to give the immune system every chance to destroy them. The maximum dose for large and fast-growing tumors is $3 \mathrm{ml}(4 \times 10$ drops $)$ of $\mathrm{D} 2$ per day. A hyper dosage should be avoided. With the uptake of 100 


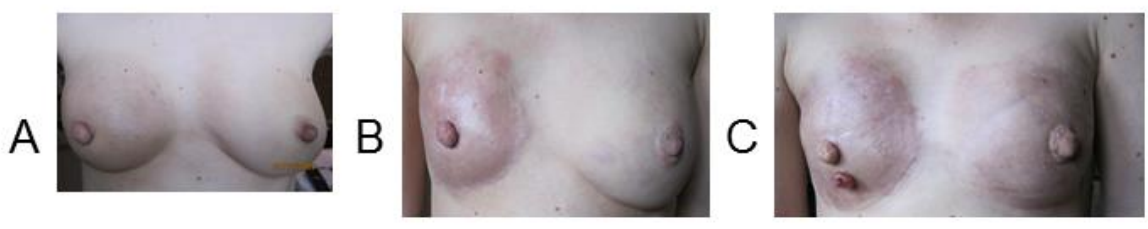

\section{$\log \mathrm{CA} 15.3$}

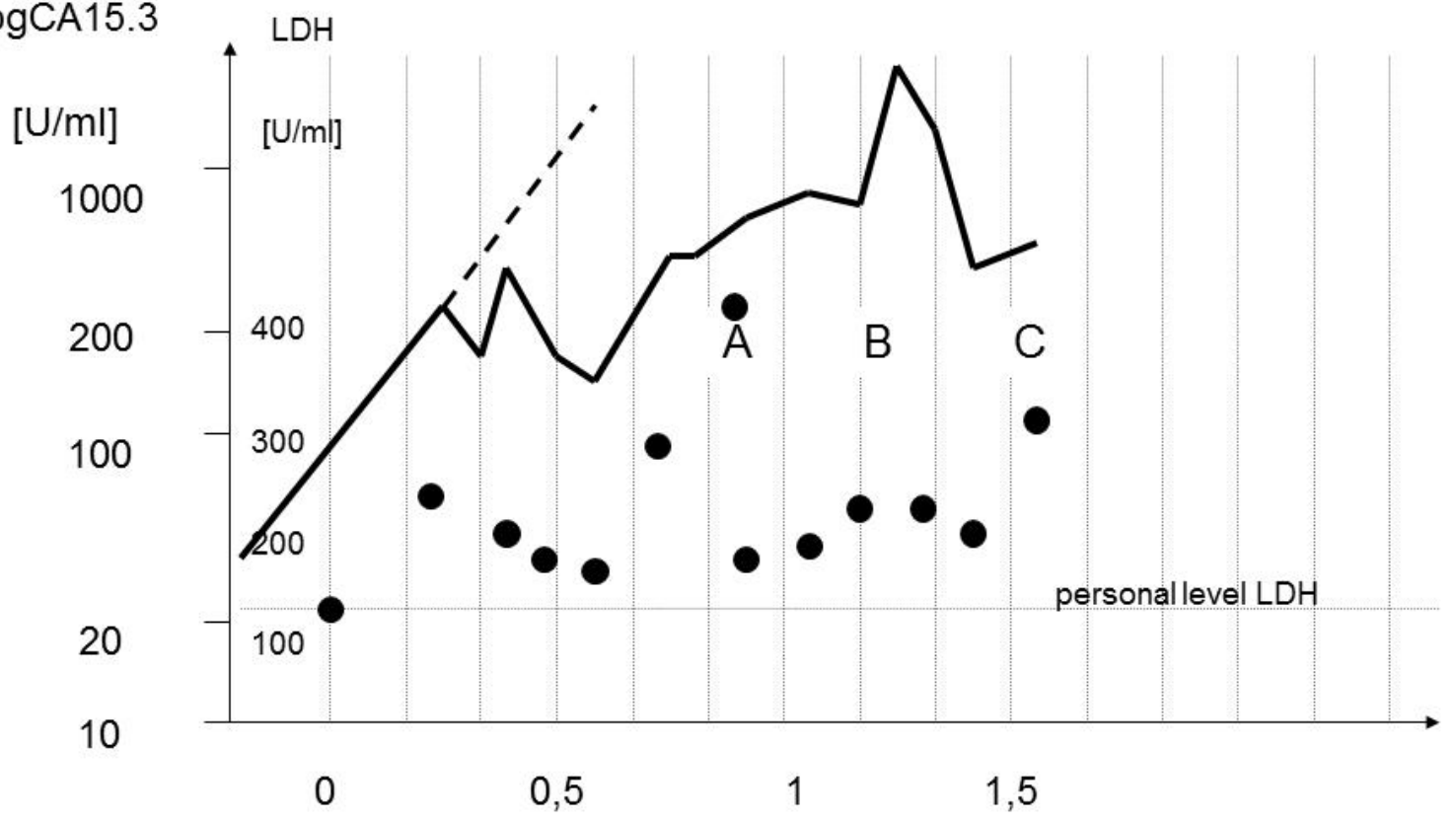

years

Fig. 1. Treatment of the patient. Outlined are the levels of the tumor marker CA15.3 (line) and LDH (dots) over time. Before amanita therapy, the tumor showed exponential growth with a duplication time of 75 days. The personal level of LDH was at $130 \mathrm{U} / \mathrm{ml}$, the upper standard limit at 200 $\mathrm{U} / \mathrm{ml}$. At time zero, therapy starts with A.phalloides (zert. Riede) [herbamedAG, foot note] and the initial dose is $4 \times 10$ drops D2 per day. Initially the increase of CA-15.3 is not affected, however, LDH increases. After three months and a total intake of $150 \mathrm{~mL}$ D2 the breasts start to become inflamed, red hot and hard. CA15.3 first declines and then increases again, together with the LDH increase, indicating lysis of tumor cells. The lymph nodes become swollen, indicating that the immune system helps to degrade tumor cells. After the uptake of $200 \mathrm{ml}$ D2 at 0.5 years, therapy was continued with 5 drops D3 per day. This leads to a further increase of CA15.3. After 0.75 months 5 drops D2 were applied per day. This leads to a cease of CA15.3. High level of LDH, swollen lymph nodes and pain reveal cellular lysis. Picture A shows the patient at this time, after the uptake of $220 \mathrm{~mL}$ D2 in total. The previously larger right breast has lost volume and the left breast starts with visible inflammation symptoms. Therapy was continued with at least 5 drops D2 per day or a maximum of $4 \times 10$ drops D2 per day, dependent on the condition of the patient. Picture B shows the patient at 1.2 years and after the uptake of $250 \mathrm{~mL}$ D2 in total. The right breast has lost most of its volume and the left breast starts to lose volume. The following increase of CA15.3 is again accompanied with high LDH, indicating tumor cell lysis. At this stage, and the uptake of $300 \mathrm{~mL} \mathrm{D2}$ in total, the patient twice faints, has a fever over 4 weeks and - for the first time during the therapy - stays home. She loses body weight, from initially $52 \mathrm{~kg}$ to $48 \mathrm{~kg}$. Lysis of cells leads to a subsequent decline of CA15.3 accompanied with high levels of LDH. 5 drops D2 are applied daily. The patient recovers quickly and reaches the initial body weight after one month - and goes back to work. She is very thirsty and drinks up to 10 liters per day. At 1.5 years the therapy is interrupted. A total of $370 \mathrm{~mL} \mathrm{D} 2$ is incorporated. Picture C shows the patient at this time. The right breast continues to shrink, a tumor wart grows out within 2 months. The right breast has lost most of its volume. During the following pause the body will recover and a new equilibrium between immune cells and tumor cells will be found.

$\mathrm{ml}$ of $\mathrm{D} 2$, the tumor should be attacked without severe side effects.

Herbamed AG in Buehler, Switzerland produces A. phalloides dilutions according to the Homoeopathisches Arzneibuch Rp 3a (HAB3a). In brief, whole mushrooms are extracted in $60 \% \mathrm{w} / \mathrm{w}$ ethanol. Standardization occurs according to HAB3a on amanitin content.

\section{RESULTS AND DISCUSSION}

Here a pilot study is presented treating a patient with mammary duct carcinoma. The 47 year old patient was born in the German Democratic Republic and has had no environmental risk for tumor development. The grandmother developed kidney carcinoma. No other tumors are reported from other direct relatives. The patient works as a secretary.

The mammary duct carcinoma was diagnosed at the age of 44 , three years prior to beginning the amanita therapy. An operation was not possible, while chemotherapy, radiation and invasive diagnostics were refused by the patient. Therefore, no histological data is available; however, amanita therapy is not dependent on this information.

Hyperthermia had been applied, followed by an increase in tumor growth activity.

Initial tumor mass at the beginning of therapy was estimated from a PET-CT to be more than $1 \mathrm{~kg}$ in the breasts. The tumor in the right breast is larger than in the left and appears as one bulky tumor mass. In the left breast three eggshape tumors appear. Additionally, multiple metastases are 
known, each $3 \mathrm{~cm}$ in diameter, adjacent to the backbone and ribcage.

Monitoring tumor marker CA15.3, LDH, and the clinical picture, different doses of amanitin were applied (Fig. 1). No additional disease was diagnosed. No other tumor specific therapy was used and no other measures or medications were necessary or administered. Adjuvant uptake of additional essential fatty acids (to enhance fluidity of cell membranes and to provide raw material for prostaglandins, i.e. immune cell hormones), and zinc (cutanous) was administered. Upon requirement, analgesics were administered.

Within a period of one and a half years, the disease can be stabilized. No damage of the somatic cells can be diagnosed. Overall, the tumor mass was reduced from an initial estimate of $1 \mathrm{~kg}$ to an estimate of $0.1 \mathrm{~kg}$. CA15.3 was stabilized to less than $1000 \mathrm{U} / \mathrm{ml}$; based on the initial exponential growth rate, if untreated the level would have been $10.300 \mathrm{U} / \mathrm{ml}$.

This new principle shows a high potential for keeping the patient alive.

\section{CONFLICT OF INTEREST}

The authors do not have any conflict of interest in the present study.

\section{REFERENCES}

Barrett JC, Oshimura M, Koi M. Role of oncogenes and tumor suppressor genes in a multistep model of carcinogenesis. Symp Fundam Cancer Res. 1986;39:45-56.

Bishop JM. Viral oncogenes. Cell. 1985;42:23-38.

Gu Y, Nakamura T, Alder H, Prasad R, Canaani O, Cimino G, Croce CM, Canaani E. The $\mathrm{t}(4 ; 11)$ chromosome translocation of human acute leukemias fuses the ALL-1 gene, related to Drosophila trithorax, to the AF-4 gene. Cell. 1992;71:701-708.

Imam JS, Buddavarapu K, Lee-Chang JS, Ganapathy S, Camosy C, Chen Y, Rao MK. MicroRNA-185 suppresses tumor growth and progression by targeting the Six 1 oncogen in human cancers. Oncogene. 2010;29:4971-4979.

Orlovsky K, Kalinkovich A, Rozovskaia T, Shezen E, Itkin T, Alder H, Ozer HG, Carramusa L, Avigdor A, Volinia S, Buchberg A, Mazo A, Kollet O, Largman C, Croce CM, Nakamura T, Lapidot T, Canaani E. Down-regulation of homeobox genes MEIS1 and HOXA in MLL-rearranged acute leukemia impairs engraftment and reduces proliferation. Proc Natl Acad Sci U S A. 2011;108:7956-7961.

Riede I. Proliferative genes induce somatic pairing defects in Drosophila melanogaster and allow replication. Cancer Genet Cytogenet. 1997;97:143-154.

Riede I. Switch Genes in Tumor Formation. DIS. 2004;87:5459 .

Riede, I. Tumor Therapy with Amanita phalloides (Death Cap): Stabilization of B-Cell Chronic Lymphatic Leukemia. J Altern Complement Med. 2010;16:1129-1132.
Rozovskaia T, Feinstein E, Mor O, Foa R, Blechman J, Nakamura T, Croce CM, Cimino G, Canaani E. Upregulation of Meis1 and HoxA9 in acute lymphocytic leukemias with the $\mathrm{t}(4$ : 11) abnormality. Oncogene. 2001;20:874-878.

Svingen T, Tonissen KF. Altered HOX gene expression in human skin and breast cancer cells. Cancer Biol Ther. $2003 ; 2: 518-523$

Yang ZQ, Liu G, Bollig-Fischer A, Giroux CN, Ethier SP. Transforming properties of 8p11-12 amplified genes in human breast cancer. Cancer Res. 2010;70:8487-8497. 